\title{
Outsourcing energy retrofitting of hotel buildings: the decision-making process
}

\author{
M.F.F. Fasna ${ }^{1, *}$, and Sachie Gunatilake ${ }^{1}$ \\ ${ }^{1}$ Department of Building Economics, University of Moratuwa, Sri Lanka
}

\begin{abstract}
Poor energy performance of existing buildings worldwide has led to a crucial need to retrofit existing buildings to minimise energy consumption. Among the existing buildings, hotels use as much as $50 \%$ of their total expenses on energy and offer significant opportunities for energy efficiency improvement. Yet, comparatively the level of implementation of energy retrofits found to be low, which has attributed to, inter alia, the absence of a clearly defined process for ensuring the delivery of energy retrofit projects and lack of proactive guidance for project teams to ensure that they make the right decisions at the right time to achieve the desired outcomes. Since many energy retrofit projects in existing hotels are carried out with the involvement of an external contractor, or an Energy Service Company (ESCO), this study focuses on investigating the decision-making process in implementing energy retrofits when the project is outsourced to an external party. An indepth case study is used to obtain insights into the critical decisions to be taken and key activities to be performed throughout the decision-making process. The findings are used to propose a step-bystep decision-making process comprising of three key phases: i.e., pre-retrofit, retrofit implementation and post-retrofit. It is hoped that the decision-making process developed in this study will serve as a roadmap for the effective adoption and implementation of energy retrofits in existing hotel buildings when an external contractor is involved.
\end{abstract}

\section{Introduction}

The importance of energy conservation and the reduction of greenhouse gas (GHG) emissions are highly stressed in the contemporary world [1]. In the building sector, existing buildings encompass the largest segment of the built environment [2] and represent the most significant opportunity for Energy Efficiency (EE) improvements [3]. Hence, enhancing the efficiency of existing buildings is identified as an essential focal point for the reduction of total energy consumption and GHG emissions [4].

Energy Retrofits (ER) aimed at making modifications to the systems, equipment or parts of a building with the intention of reducing the use of energy [5-6]. Further, retrofitting of a building provides excellent opportunities for improved EE, reduced GHG emissions, increased staff productivity, reduced maintenance costs and better thermal comfort [7-8].

Despite the existence of a large number of building ER technologies [7] and numerous associated benefits [9], still, the level of implementation of ER is comparatively low [10]. This has been attributed, inter alia, to the absence of a clearly defined process for ensuring the delivery of ER, lack of proactive guidance for project teams to ensure that they make the right decisions to achieve the desired EE outcomes [11] and conducting ER projects in an ad hoc basis without a systematic decision-making process [12]. Hence, it is clear that informed decision-making is vital for improving the energy performance of existing buildings [13] as well as to propagate the benefits of retrofits [14]. Concerning research, however, most of the attention so far has been focused on investigating the technological aspects of EE measures with little focus given towards exploring the decision-making aspects of the same [13]. Therefore, this paperis aimed at developing a decisionmaking process to support effective adoption and implementation of ER in existing buildings.

Among commercial buildings, luxury hotels use as much as $50 \%$ of their total expenses on energy due to their extended operation [15] and thus offer many opportunities for EE improvement [16]. Sri Lanka Energy Managers Association [15] estimates this saving potential to be around $20 \%$. Hence, among the existing buildings, the focus of this study was limited to existing hotel buildings.

Lack of personnel and internal expertise have been identified as key reasons for the poor implementation of ER projects in existing hotel buildings [17]. This has led many hotels to outsource their ER projects to external parties mainly Energy Service Companies (ESCOs). Similarly, it has ascertained that by far, a growing number of ER in the commercial sector implemented as a result of Energy Performance Contracts (EPCs) between commercial building owners/managers and ESCOs [18]. Hence, this study limited its focus on investigating the decision-making process in implementing ER when the project is outsourced to an external party.

\footnotetext{
* Corresponding author: fasna.fm2013@gmail.com
} 


\section{Decision-making process for the adoption and implementation of ER}

Decision-making is the thought process of selecting the most suitable option/s from the available options [19]. In making rational decisions, the decision-making process should be goal-oriented; follow a systematic procedure of action and use clear, methodical rules; and the considerations in the decision-making process should be based on information which is as objective and complete as possible [20].

Besides, Herrmann [21] added that when the number of alternatives is significant and, multiple criteria are relevant, formal techniques must be employed to identify the best alternative. Similarly, a wide range of technological options with varying benefits is available to increase the EE of buildings [22] and to evaluate such options and thereby to determine the best option a list of criteria can be used [11]. Hence, ER projects should be approached systematically to achieve maximum benefit out of those projects [23].

In the literature, some authors have given concern towards identifying the process to determine the most suitable ER measures for a particular project (E.g. [24], [25]) whereas others have made an attempt to come up with a systematic approach for identifying, determining and implementing ER projects (E.g. [7], [26]). However, Crilly et al. [27] have concluded in their study that to make informed decisions on ER, a comprehensive understanding of the whole process is essential.

Among the available processes for the adoption and implementation of ER projects, the process suggested by Ma et al. [7] seems to cover all the key phases and hence, provides a useful basis for understanding the decision-making process of ER projects in this study. According to them, the overall process of a building retrofit comprises of five major stages: as, project setup and pre-retrofit survey; building energy auditing and performance assessment; identify possible retrofit measures; site implementation and commissioning; and validation and verification. Hwang et al. [28] have defined 'pre-retrofit' as the state before the implementation of a retrofit project and 'post-retrofit' as the state after the retrofit completion. Using this as a basis, the five major stages identified by Ma et al. [7] can be classified into three different phases as preretrofit (which includes project setup and pre-retrofit survey; building energy auditing and performance assessment; and identifying possible retrofit measures), retrofit implementation (which includes site implementation and commissioning) and post-retrofit (which includes validation and verification) phases.

As a whole, review of the literature disclosed that there is a dearth of research focusing on investigating the activities and decisions to be made in the ER decisionmaking process, and different stakeholders who should be involved in making such decisions and activities. Most of the attempts made by the authors so far to derive a systematic approach for ER projects have resulted in deriving only key stages of the project while only very few authors like Ma et al. [7] have come up with a comprehensive process for ER projects. Besides, the processes developed in the existing literature do not clearly distinguish the process to be followed when an external contractor is involved in the ER decisionmaking process. Further, a gap remains as to how the decisions and activities relating to ER are carried out in practice in the hotel sector when an ER project is outsourced to an ESCO; and by whom such decisions and activities are to be made, which will elicit in this study via empirical investigation.

\section{Research Methodology}

The research used a single case study of an ER project done in a leading five-star hotel in Sri Lanka. Since indepth information is needed to derive the decisionmaking process pertinent to the outsourced scenario, the study focused on conducting a single case study by employing sufficient time in investigating the decision making aspects.

Having considered the necessity of capturing the best practices followed by the organisation to retrofit their facilities, while selecting the case priority given for the hotels that have received the Sri Lanka National Energy Efficiency Awards for their ER projects. Besides, during case selection focus was limited to medium retrofits. Because, due to the nature of operation of hotel buildings and their saving potential, in practice, hotel buildings mainly undertake conventional retrofits which referred to as 'medium retrofits' $(6,18)$.

This selected ER project was the first commercially guaranteed ER project in Sri Lanka. This project aimed at retrofitting the air-conditioning system of the particular hotel which took almost a year for completion and resulted in $21 \%$ reduction in total electricity consumption. The ESCO who led this project was an Australian based Energy Conservation Company and registered under the Sri Lanka Sustainable Energy Authority.

The central unit of analysis of this study is the 'decision-making process for the adoption and implementation of ER projects.' Data collected from five semi-structured interviews with respondents selected from the roles played and their level of involvement in the decision-making process of the selected ER project. The selected respondents include those directly involved in decision-making. The details of the respondents given in Table 1.

Table 1. Details of the respondents.

\begin{tabular}{llll}
\hline Respondent & $\begin{array}{l}\text { Profile of the } \\
\text { respondent }\end{array}$ & Roles played & $\begin{array}{l}\text { Years of } \\
\text { experience }\end{array}$ \\
\hline R1 & $\begin{array}{l}\text { Chief Executive } \\
\text { Officer (CEO) }\end{array}$ & $\begin{array}{l}\text { ESCO, Supplier, } \\
\text { Energy Auditor, Cost } \\
\text { Consultants }\end{array}$ & 18 \\
\hline R2 & Director Engineer & Owner/Client & 31 \\
\hline R3 & Chief Engineer & Facilities Manager & 26 \\
\hline R4 & $\begin{array}{l}\text { BMS and Facilities } \\
\text { Engineer }\end{array}$ & $\begin{array}{l}\text { Building Services } \\
\text { Engineer }\end{array}$ & 03 \\
\hline R5 & $\begin{array}{l}\text { Chief Technical } \\
\text { Advisor - Energy }\end{array}$ & Industry institution & 25 \\
& & & \\
\hline
\end{tabular}

The structure of the interviews intended to allow the respondents to specify the adopted process in their own 
words, ensuring that the external influences are limited. Analysis of the semi-structured interview data was done through code based content analysis using N-vivo computer software. Findings from the case study analysis presented in the following section.

\section{Results and discussion}

Case study analysis revealed the key activities to be performed and key decisions to be made in an ER project led by ESCO, which could align within the five stages of ER decision-making process identified through the literature (See Figure 1). The key findings discussed in the following sections.

\subsection{Pre-retrofit phase of ER projects}

As discussed in section 2, the pre-retrofit phase of an ER decision-making process comprised of three stages as 'project set-up and pre-retrofit survey,' 'building energy auditing and performance assessment,' and 'identification of ER measures.' Though conducting a pre-retrofit survey has been highlighted in the stage of project set-up and pre-retrofit survey [7], none of the respondents has specified the practice of conducting a pre-retrofit survey. Thus it is possible to deduce that this particular stage should be termed as 'project set-up stage.'

Project set-up: is the first stage of the process and represents the initial activities to be performed by the ESCO like choosing a particular building for retrofitting, and having discussions with the respective parties to offer the willingness to assist them in reducing their energy consumption.

As noted by R2 and R3, an ESCO involved in an ER project in 2 different ways, i.e. 1) client organisation identifies the need of retrofitting and decide to obtain the assistance of ESCO due to their lack of capability or any other reasons; and 2) ESCO by themselves target the heavy users of energy, approach the particular client and offer their willingness to assist them in reducing their energy consumption. Figure 1 depicts the second instance as in this particular case it was the ESCO who took the initiatives for this particular ER project.

In this case, at first, the ESCO has selected the particular hotel building as the suitable case for retrofitting since they believed that the heavy users of energy are where ESCOs need to go and make EE improvements (R1). After targeting and choosing the particular hotel as a heavy user of energy, the ESCO had to decide 'whether to approach the client and convince him to retrofit his facility or not,' and the process initiated after ESCO approaching the particular organisation due to its heavy energy usage.

'Whether to launch a retrofit project' is a key decision to be made by the client in the project set-up stage [10]. However, since in this project, the need of retrofitting the particular facility identified by ESCO, the key decision that they had to make was "whether to approach the client and convince him to retrofit the facility.'

Building energy auditing and performance assessment: is the second stage of the process and aimed at clearly identifying the saving potential of the facility and thereby to select the suitable systems for retrofitting.

This stage begins with the request made by ESCO to the client (i.e. 'director engineer') to do the initial walkthrough audit with the intention of getting an overall understanding on energy consumption pattern and thereby to identify whether there are any saving potentials. In such instance, the client had to make a decision which is 'whether to allow the ESCO to do the audit.'

R1 has divulged that depending on the findings of the initial walkthrough audit; they believed that conducting an in-depth audit would be useful in obtaining an excellent understanding of the performance of the facility. Thus, by incorporating the findings of the walkthrough audit, ESCO has given an offer letter to the client by requesting permission to conduct an in-depth audit. This implies another decision to be made by the client which is 'whether to allow the ESCO to do the indepth audit.'

During the in-depth audit, the ESCO has studied the building's mechanical and electrical systems; construction, operation and maintenance procedures; particular problems faced by the occupants; and required repairs, via which energy saving potential of the facility identified. Following this, the most suitable system for retrofitting is determined based on the level of efficiency of each system, each system's level of energy consumption, and their energy-saving potential.

Hendron [26] states that a preliminary analysis before the actual audit will indicate the overall potential for improvement. Similarly, in this case, the ESCO has first performed a walkthrough audit based upon which the potential for proceeding with an ER project determined.

'Whether the building should be retrofitted or not' is a decision to be made in the stage of building energy auditing and performance $[7,10]$. However, since in this ER project the in-house employees belong to the client also has already realised that their energy performance is poor, they did not have to make such a decision.

'Whether to allow the ESCO to do the audits' is the key decision made by the client in this stage mainly after the ESCO's request to do the audits in the client's premises. Also, based on the results of the energy audits, the ESCO had to decide the systems retrofitted under this ER project, which is so far have not been identified as a decision in the existing literature.

Identification of ER measures: is the stage which includes the activities to be performed to derive the most suitable ER measures and thereby to develop a plan for implementation of the selected ER measures.

'What would be the most suitable measures to retrofit the particular systems' is the primary decision to be made by ESCO in this stage. This has been done after selecting the most suitable system for retrofitting. 


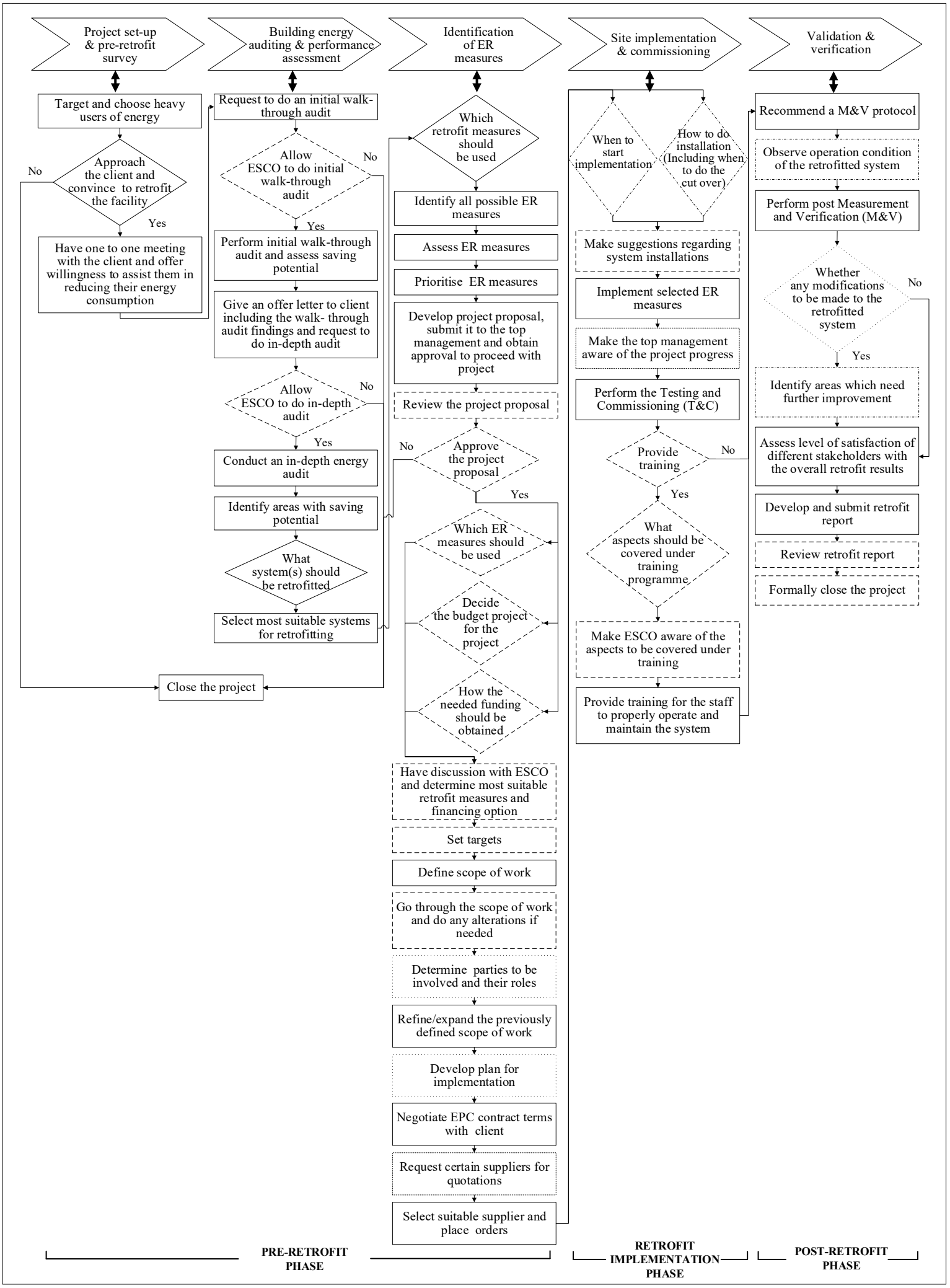

\section{Legend:}

$\sum$ Key stages of ER decision-making process Key activities to be performed by ESCO

O..... Optional activities to be performed by ESCO or in-house staff

- Key activities to be performed by Client or in-house team

i... Activities to be performed performed by both Client and ESCO
Best practice activities affirmed by the respondents Decisions to be made by ESCO

Decisions to be made by Client or in-house team Decisions to be made by both Client and ESCO Activity flow

Fig. 1. Decision-making process of ER project if the ESCO leads the project. 
R3 has disclosed that ESCO assessed the identified possible ER measures concerning the needed cost, saving that could be achieved, the lifetime of each measure, and each measure's impact on operation and maintenance cost. Besides, the effect of each measure on building operation, how the implementation of each measure could impact the occupants' comfort, and what would be the training requirements in case of the implementation of each measure were also considered while assessing the identified ER measures as has been mentioned by R1. After the assessment, the ER measures were prioritised based on the feasibility of implementation, payback period and return on investment.

Afterward, ESCO has developed the project proposal including full cost vs. savings analysis for all the possible ER measures, the suggestion of most suitable measures for implementation, and all the available financing options to fund the project, which then submitted to the top management for approval. Since the client was satisfied with the findings presented by ESCO, the client has decided to proceed with the project. Hence, the client, in discussion with ESCO had selected the most suitable ER measures, the total amount of money to spend on the project and the most suitable way of funding the project.

Afterward, the client has established the targets for the project based on the proposal given by ESCO, i.e., the savings percentage guaranteed by the ESCO. Then, ESCO has prepared the detailed scope of work (i.e., the tasks to be performed under the particular ER project) which is then reviewed by the client with the intention of making alterations if needed.

None of the respondents from this case has explicitly noted 'determining the parties to be involved in the ER project along with their roles' as an activity undertaken in this ER project. Nevertheless, considering the higher variety of stakeholders that would be involved in ER projects which outsourced to external parties, this has been noted by $\mathrm{R} 5$ as an activity that would be an added benefit for the ER projects led by ESCOs mainly after defining the scope of work.

A1 in this stage highlights refining and expanding the previously defined scope of work. Though in this case no any plans were developed to properly proceed with the implementation, 'developing a plan to proceed with the project implementation properly' was emphasised by $\mathrm{R} 3$ as a good practice to be adopted in ER projects mainly after finalising the scope of work. Afterward, the ESCO has negotiated with the client and determined the EPC contract terms. Then the ESCO has chosen the most suitable supplier to deliver the needed pieces of machinery and have placed the orders. However, R1 has affirmed that if an organisation does not have enough knowledge on the level of credibility of the suppliers, 'requesting certain suppliers in the market to provide quotations' would be useful in selecting a suitable supplier.

One of the critical steps in ER is the selection of most suitable ER measures among a large number of possibilities [22], for which organisations should: begin with a workable list of all the measures [26]; determine the criteria and factors that should be considered to analyse the ER measures [11]; analyse the identified ER measures [7, 13]; and prioritise the ER measures based on the relevant energy-related and non-energy-related factors [7]. Though this particular case has performed all of these activities to determine most suitable ER measures, 'determining the criteria and factors that should be considered' is not being performed as a separate activity, slightly different types of criteria/aspects were considered while assessing the retrofit measures.

Mohammadpour et al. [29] have insisted the need to set a target for ER project before deciding most suitable ER measures. However, in this case, the targets for the project had been set only after the most suitable retrofit measures have been determined. This is mainly due to the reason that in this particular case, ESCO, who has identified the saving potential, has come up with possible ER measures and the benefits that could be gained (i.e. level of saving, GHG emission reduction etc.) and submitted the findings to the client based upon which the client has chosen the most suitable ER measures and has set the targets.

'Defining the scope of the work' is a key activity to be performed in the project set-up stage [7]. However, in this ER project, the ESCO has defined their scope of work after client determining the suitable ER measures for implementation.

Ma et al. [7] insisted the vitality of developing an action plan to make the client aware of the selected ER measures. In ER projects led by ESCOs, the role of ESCO is to facilitate the client in making the right decisions. Hence, in this case, ESCO has developed a project proposal along with the suggestions of the most suitable ER measures, based on which client determined the suitable ER measures.

As a whole, it is interesting to note that, though setting project targets and defining the scope of work are identified as the activities to be performed in the stage of project set-up and pre-retrofit survey [7], in practice in ESCO led ER projects these are being done mainly after determining the suitable ER measures. Besides, 'developing a plan to proceed with the project implementation properly' was ascertained as a best practice activity to be performed in this stage which elicited through the case study analysis.

Based upon the results of the building performance assessment and energy auditing, "which ER measures to be implemented' $[7,30]$ and 'how much should be spent on retrofitting' are to be decided [30]. Similarly, case study analysis disclosed that in this stage the client had to make both of these decisions. Besides, 'how the needed funding should be obtained' and 'whether to approve the project proposal' are other key decisions to be made by the client in this stage in which the latter is made mainly after reviewing the project proposal submitted by ESCO.

\subsection{Retrofit implementation phase of ER projects}


Site implementation and commissioning: is the only stage falls under this phase and involves the activities to be performed to ensure successful implementation and operation of the selected ER measures.

Case study analysis revealed that the main decisions made by both client and ESCO in retrofit implementation phase are 'when to begin with the implementation of the selected retrofit measures' and 'how to do the installations of selected retrofit measures.' Findings disclosed that 'when to do the cut-over' without causing interruptions to hotel operation is another decision made in this phase. Since doing cut-over is part of system implementation, it could be deduced that it should be an aspect to be covered while making decisions on when and how to do the system installations.

Case study findings revealed that the client organisation had given their input regarding system installation before the implementation, which was perceived as necessary to 'ensure the proper accessibility for future operation and maintenance' (R4). Monitoring of the installation works being done by the ESCO by the client had helped to ensure the successful installation of the system as well as minimise the interruption caused to hotel operations. Further, R4 affirmed that after the implementation of the selected ER measures making the top management aware of the project progress is an activity to be performed either by ESCO or by the building services engineer attached to the client organisation.

After the successful implementation and commissioning, the client organisation of this case had determined whether any training should be provided and what are the aspects that should be covered during the provision of training to the staff and subsequently brought them to the ESCO's attention. ESCO has then provided the required training for the staff.

'Site implementation' and 'testing and commissioning' are the main activities to be performed in retrofit implementation phase [7]. Besides, the activities ascertained from case study analysis as to be performed in this phase are: make suggestions regarding system installation; make top management aware of the project progress; make ESCO aware of the aspects to be covered under the training; and provide training for the staff to operate and maintain the system (Refer Figure 1).

As has been disclosed by Liang et al. [10], 'when and how ER should be implemented' is the main decision made by both client and ESCO in the retrofit implementation phase. Also, in this phase client had to decide 'whether any training should be provided' and 'what are the aspects that should cover under training programme' (Refer Figure 1).

\subsection{Post-retrofit phase of ER projects}

Validation and verification represent the final stage of the ER decision-making process which falls under the post-retrofit phase where the level of success of ER project evaluated and modifications made are considered.
Findings revealed that in this phase, ESCO had suggested suitable Measurement and Verification (M\&V) followed by the client. Then they have 'observed the operation condition of the retrofitted system' to minimise the complaints from the occupants and staff. Afterward, this particular case has conducted post $\mathrm{M} \& \mathrm{~V}$ by 'observing energy consumption patterns and keeping records' and then 'reviewing project results and determining the level of success.'

R2 disclosed that after performing post $M \& V$, assessing 'whether any alterations to be made to the retrofitted system' to enhance its performance would be beneficial in ensuring the continued attainment of the saving from the particular retrofitted system. Hence, it can be deduced that in an outsourced scenario, if the ESCO recognise the need of making modifications to the retrofitted system, they should make attempts to identify the areas which need further improvements along with the involvement of the client.

Case study analysis disclosed that conducting a postoccupancy survey to assess the level of satisfaction of different stakeholders with the overall retrofit results is another key activity performed by ESCO. Afterward, a 'retrofit report' had been developed by ESCO, incorporating the key findings of the project, which is in turn reviewed by the respective stakeholders. Since the client of this particular ER project was very much satisfied with the outcome of this project, they have formally closed the project.

Performance of post M\&V, the conductance of postoccupancy survey, preparation of the retrofit report, client review [7] and finish retrofit [10] were identified as activities to perform in this stage. Similarly, all of these activities performed in this particular case. In addition to these, the case study analysis revealed some more new activities like, recommend an M\&V protocol; observe the operation condition of the retrofitted system and identify the areas which need further improvement.

Hendron [26] has disclosed that 'what kind of modifications to made to the retrofitted system' is a decision to be made in post-retrofit phase and R2's assertion on determining the alterations to be made to the retrofitted system appears to be in-line with this.

\section{Conclusions}

By employing a single in-depth case study, this study derived the ER decision-making process that can be adopted by the organisations to retrofit their facility under the outsourced scenario. The identified process comprises of five key stages whichare classified into three phases as pre-retrofit, retrofit implementation and post-retrofit. This developed decision-making process includes: thirty-three (33) key activities and two (2) optional activities to be performed by the respective parties; two (2) best practice activities affirmed by the respondents; thirteen (13) key decisions to be made by respective parties; and a decision suggested by the respondents as good to perform in the respective stage (Refer Figure 1). Besides, the case study analysis revealed two major involvement options of ESCO in an 
ER project, i.e., 1) client identifies the need of retrofitting and decide to obtain the assistance of ESCO mainly due to their lack of capability, and 2) ESCO identifies the need of retrofitting of the particular facility and approach the client, which was the case in this selected ER project. Further, it has ascertained that in ER projects led by ESCO both in-house team and ESCO have their prominent roles to be played concerning decision-making as well as the performance of activities. As a whole, this research has made a valuable contribution to knowledge by proposing a step-by-step decision-making process which could serve as a roadmap for the effective adoption and implementation of ER in existing hotel buildings when an external contractor is involved.

This work supported by the Senate Research Committee of the University of Moratuwa, Sri Lanka under Grant SRC/LT/2017/18.

\section{References}

1. B. E. Choi, J. H. Shin, J. H. Lee, S. S. Kim, Y. H. Cho, Energies, 10, 324 (2017)

2. European Climate Foundation (ECF), Assessing Europe's Building Stock (2013). Retrieved from https://europeanclimate.org/bpie/

3. Y. Xing, N. Hewitt, P. Griffiths, Renew. Sust. Energ. Rev., 15, 3229-3236 (2011)

4. X. Liang, G. Shen, L. Guo, Int. J. Environ. Res. Public Health, 12, 13823-13842 (2015)

5. T. Ashrafian, A. Z. Yilmaz, S. P. Corgnati, N. Moazzen, Energ. Buildings, 120, 58-77 (2016)

6. S. Chunduri, Development of planning and design phases of an integrative building lifecycle process model for advanced energy retrofit projects (Doctoral dissertation). Retrieved from https://etda.libraries.psu.edu/files/final_submis sions/9943, (2014).

7. Z. Ma, P. Cooper, D. Daly, L. Ledo, Energ. Buildings, 55, 889-902 (2012)

8. M. Picco, R. Lollini, M. Marengo, Energ. Buildings, 76, 497-505 (2014)

9. J. Hou, Y. Liu, Y. Wu, N. Zhou, W. Feng, Energ. Policy, 88, 204-215 (2016)

10. X. Liang, Y. Peng, G. Q. Shen, J. Clean. Prod., 137, 1300-1312 (2016)

11. P. Gultekin, C. J. Anumba, R. M. Leicht, Int. J. Energ. Sector Manag., 8, 434-455 (2014)

12. S. Hall, Renew. Energ., 67, 109-118 (2014)

13. R. Ruparathna, K. Hewage, R. Sadiq, Renew. Sust. Energ. Rev., 53, 1032-1045 (2016)

14. W. Swan, P. Brown, Retrofitting the Built Environment (Wiley, Salford, 2013).
15. Sri Lanka Energy Managers Association (SLEMA), Energy management guide (Sri Lanka Sustainable Energy Authority, 2009)

16. P. Xu, E. H. Chan, Q. K. Qian, Facilities, 30, 432-448 (2012)

17. P. Xu, E. H. Chan, Barriers to implementing energy performance contracting (EPC) mechanism into hotel buildings retrofit in China (2011, June)

18. Sustainable Energy Authority of Ireland (SEAI), Unlocking the Energy Efficiency Opportunity (June 2015)

19. Business dictionary, WebFinance Inc. Retrieved from

http://www.businessdictionary.com/definition/d ecision-making.html, (2018).

20. R. Grünig, R. Kühn, In Solving Complex Decision Problems. Springer, Berlin, Heidelberg. 25-34 (2017).

21. J. W. Herrmann, Wiley StatsRef: Statistics Reference Online, 1-9 (2014).

22. E. Asadi, M. G. Da Silva, C. H. Antunes, L. Dias, Energ. Buildings, 44, 81-87 (2012)

23. T. Bruce, J. Zuo, R. Rameezdeen, S. Pullen, Struct. Survey, 33, 150-166 (2015)

24. D. Kolokotsa, C. Diakaki, E. Grigoroudis, G. Stavrakakis, K. Kalaitzakis, Adv. Build. Energ. Res., 3, 121-146 (2009)

25. M. Syal, D. Duah, S. Samuel, M. Mazor, Y. Mo, T. Cyr, J. Constr. Eng. Manage., 140, 04013030 (2014)

26. B. Hendron, (2013). Advanced Energy Retrofit Guide Practical Ways to Improve Energy Performance - Grocery stores. Retrieved from National Renewable Energy Laboratory (NREL) Retrieved from: https://www.nrel.gov/docs/fy13osti/54243.pdf

27. M. Crilly, M. Lemon, A. J. Wright, M. B. Cook, D. Shaw, Energ. Environ., 23, 1027-1055 (2012).

28. B. G. Hwang, X. Zhao, Y. L. See, Y. Zhong, Proj. Manage. J., 46, 76-89 (2015)

29. A. Mohammadpour, C. J. Anumba, J. I. Messner, Health Environ. Res. Des. J., 9, 68-85 (2016)

30. Jafari, V. Valentin, Build. Environ. (2017), (to be 